FEATURES

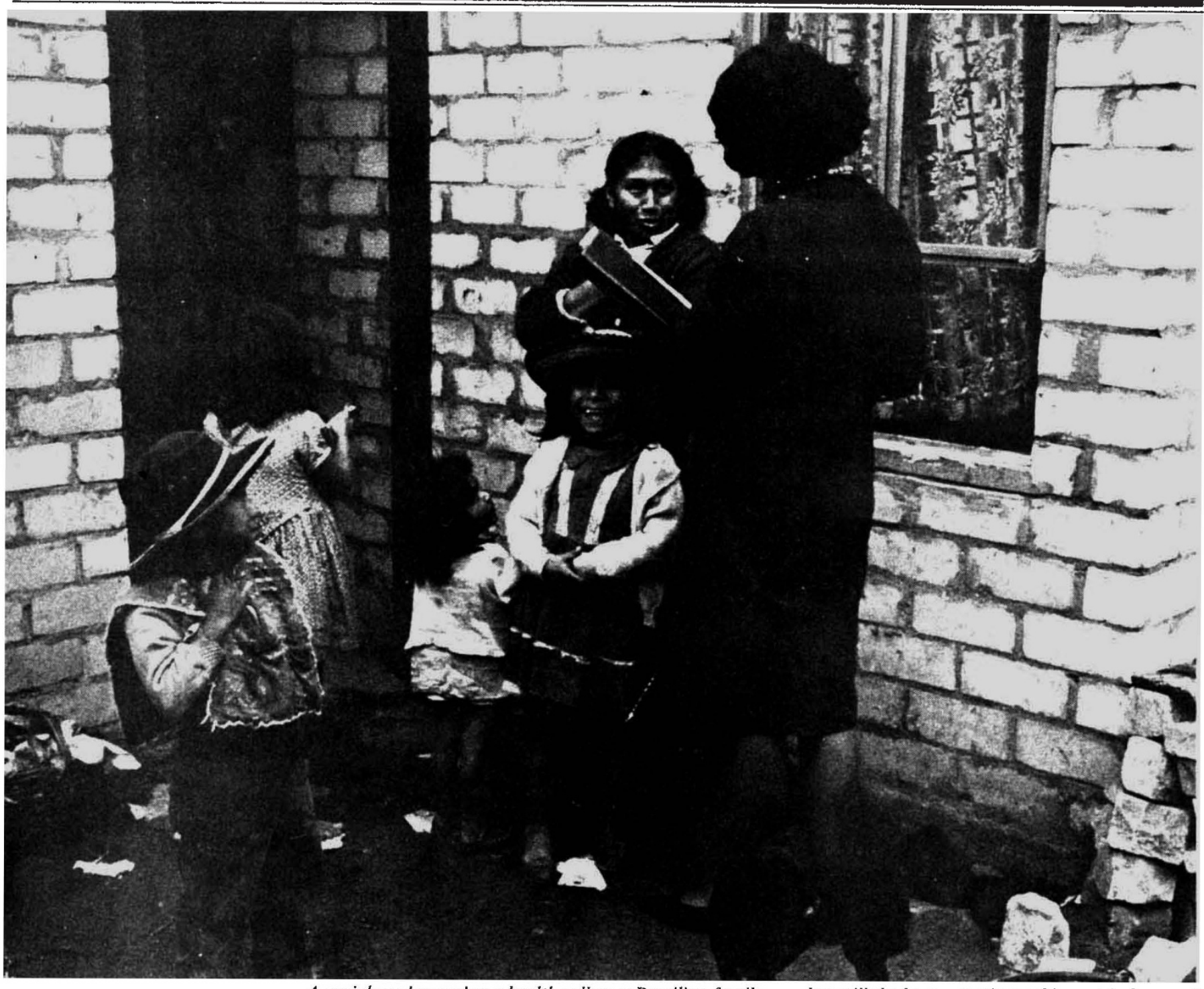

A social worker makes a health call on a Brazilian family . . but will the bureaucratic machine get in her way?

\title{
Brazilian paralysis: the real disease
}

AFTER being invited to work in Brazil by the country's Minister of Health in January, received with official honours by the President of the Republic, and feted as a Nobel prize-winner (which he is not), Dr Albert Sabin, developer of the oral antipolio vaccine, has left the country a disillusioned man. The muddle, inefficiency and sheer obstructiveness of the Brazilian Health Ministry proved too frustrating for Sabin to bear, and he has returned to his Charleston, Carolina, laboratory without taking leave of Health Minister Valdir Arcoverde.

"In truth," he commented, "it is difficult to take leave of a man who does not let himself be approached."

By Sabin's account, the history of Brazil's approach to its regular epidemics of polio is one of garbled statistics and
Health care in Brazil is not simply a matter of science and sound management. It is a matter of politics. Maurice Bazin reports on a case history - the 'Sabin episode'

official indifference to the plight of the thousands of children who still contract the disease. And he has said as much in a letter to President Figuereido.

"Bureaucratic problems of various types do not permit that this work be properly developed," he complained. "I must emphasise to your Excellency that this same bureaucracy was responsible for the failures in combating poliomyelitis in the past, and, as for the present, I have strong reasons to doubt that the next attempts will be successful."

The President has not replied.

The first major problem Sabin encountered during his two-month stay in Brazil was the impossibility he found in obtaining an estimate, however approximate, of the scale of the polio problem over the preceding ten years.

He pointed out to the Health Ministry that statistics published during that period by the Institute of Geography and Statistics (IBGE) on the one hand and the Health Ministry on the other differed by factors "'at times as high as 60 and 170". Brazil's reports to the World Health Organization showed 15,000 cases of polio per year from 


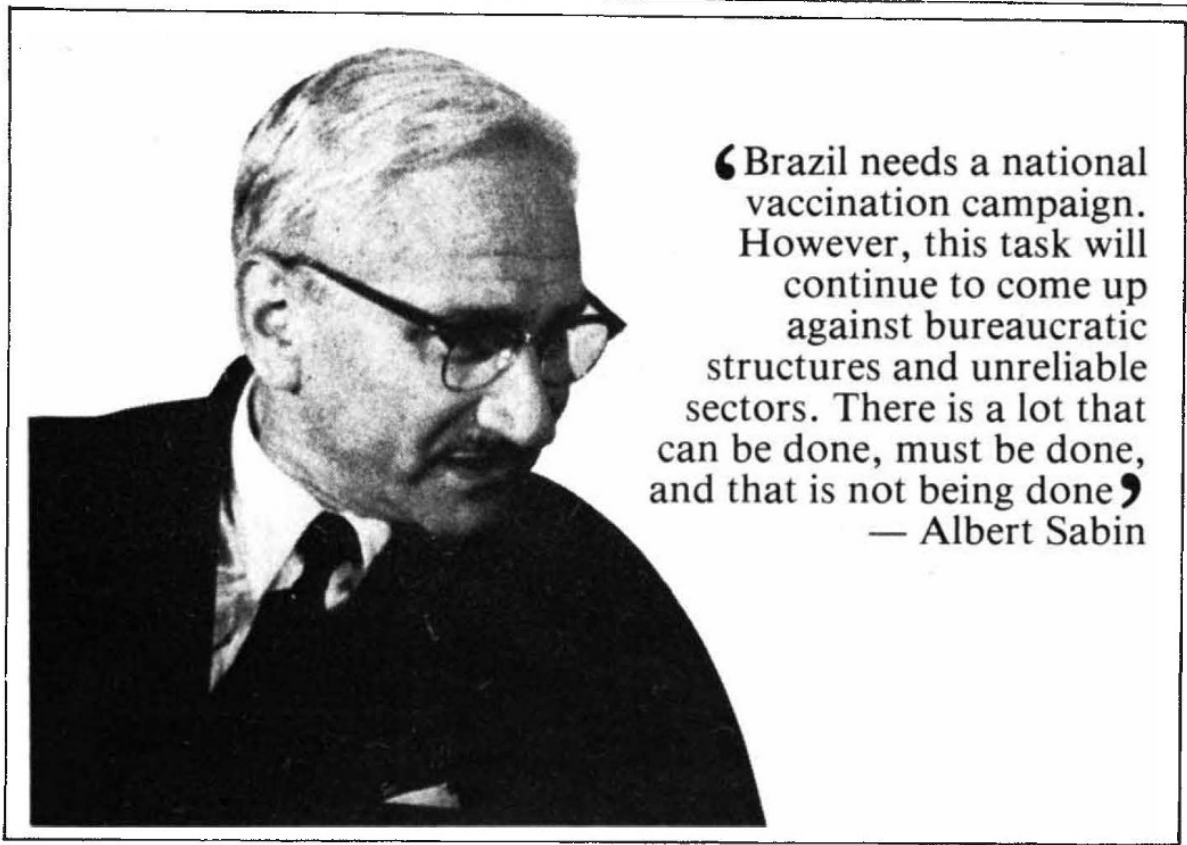

1969 to 1972 followed by an abrupt decline to 2,100 cases per year from 1973 up to the present. Could this effect be the reflection of a national immunization campaign carried out in 1971? Looking through the records, Sabin found out that the high figure came from the IBGE whose data was transmitted to WHO up to 1972 , while the low figure came from the Health Ministry's own statistics. The apparent drop corresponded to no more than the switch in data sets. Furthermore, since 1975, IBGE had been forbidden to supply any more statistics about polio.

"Nobody lied or manipulated the data," he said, "but the whole truth was not told. The officials of the Health Ministry are guilty of breach of duty because they did not inform the public about the change from one set of statistics to another. And still now they continue to give out improper information to WHO."

While working with a local vaccination campaign Sabin heard that his proposal for obtaining realistic statistics about polio incidence from a survey of school children was considered by the ministry to be "of dubious statistical value", although it had been approved by the minister six weeks earlier. But he organized a local statistical evaluation of the incidence of polio for 1969-72 and 1973-76 by looking for sequels of paralysis in children 10 to 11 years of age and six to seven years of age respectively in the Federal District around Brasilia today.

He enlisted the participation of local doctors and school personnel and found 57 cases of clear paralytic sequels in a sample of 25,000 children. From the detailed data, which represents a minimum evaluation, he could conclude that the IBGE statistics for these periods were closer to reality than those of the Health Ministry, which were at least five times below the true level.

Sabin's own data, however, are certainly still very much below a realistic estimate of the number of polio cases because they rely upon a sample of children presently in schools. In the poor districts around Brasilia many children do not go to school, and physically maimed children are often beggars in the streets and not registered school children. The only technical comment that minister Arcoverde made after Sabin made his results public at the end of March was:

"Dr Sabin is an excellent epidemiologist, however, he is no a statistician." To which Sabin replied publicly: "The Minister says that the ministry's statistics are satisfactory; I say it's completely untrue."

In the course of his investigation in the Federal District, Sabin found out that $88 \%$ of the children had contracted polio before two years of age and $45 \%$ before reaching one year, and that parents only knew of it when they noticed that their child had difficulty in starting to walk. As he went to the slum satellite cities of the Federal District and around Brasilia, diagnosing the origin of children's physical deformities, he could remember that official statistics reported no polio cases outside the capital proper during 1976, 1977 and 1978. Today, he noted, the industrial suburbs of the city of Sao Paulo have a polio incidence five times higher than the city proper.

Using the weekly reports of polio cases for different states of Brazil, Sabin found that epidemics appeared to last much longer than in European countries, at times up to six months or more. However, looking with care at the geographical origin of the reported cases, he could prove that an epidemic propagates across a state and lasts the customary three to four weeks in each locality. He therefore proposed a plan of action to stop the ongoing epidemics in the state of Santa Catarina in the south of Brazil, which he had been called to help control in January. The state's health secretary mobilized thousands of school teachers, policemen and community members to carry out a massive vaccination in one day in the communities immediately in front of the wave of contamination.

"We learnt that we could not do a vaccination in one day because the statistics about the number of children in the community were wrong. In some places we had vaccinated $110 \%$ of the children! But by the second day we reached almost all children, with teachers going door to door all day in the hot sun." Three weeks later the last hospital admittance for polio was registered in Florianopolis, the state capital.

Open conflict between the scientist and the minister never occurred. Health bureaucrats, comfortably installed in their futuristic buildings in Brasilia, continued smiling to the scientist, but stopped answering his memoranda. In a mixture of efficiency and idealism, Sabin would announce in a memo that there were no steel lungs available to save children with affected respiratory muscles outside the cities of Rio and Sao Paulo, indicate how to recover the huge lungs which were used in the US before vaccination existed, and where to acquire new plastic models. $\mathrm{He}$ included in the memo the telephone numbers of the manufacturers.

"Unfortunately, these recommendations dissolved away in bureaucratic side tracts" he wrote in his open letter to the President of the Republic.

At the same time, the Society of Pediatrics of Brasilia declared that "vaccination campaigns are never executed adequately for administrative reasons mixed with politics."

Sabin's letter to the President added: "Brazil needs a national vaccination campaign, organised in a highly efficient way and conducted every year. However, this task will continue to come up against bureaucratic structures and unreliable sectors. Just like in military operations, inexact information about enemy forces can bring about disasters; the same occurs when you face an epidemic disease . . . I have met in Brazil dedicated and competent men and women, capable of carrying through this task. I accompanied them in Goiás, Santa Catarina, Paraná and the Federal District, and I personally observed the contrast between their work and that of the official bureaucracy ... There is a lot that can be done, must be done, and that is not being done."

Despite Sabin's efforts the fundamental social problem remains of how to protect a whole population through a lasting organized effort of routine vaccination. To contribute to this effort was part of Sabin's plans for 1980 . It is now very doubtful that anything will come of it.

For saying aloud what officials in power were not interested in hearing, Sabin is now back home, and his data on polio in Brazil will be published in English-speaking professional magazines only. The president of the Society of Medicine and Surgery of Rio has compared the "Sabin episode"' to the case of Galileo. 